\title{
Teaching Calculational Logic
}

\section{(Education Session)}

\author{
D. Gries \\ Computer Science, Upson Hall \\ Cornell University \\ Ithaca, NY 14853, USA \\ gries@cs.cornell.edu
}

\begin{abstract}
For the past four years, we have been teaching logic and discrete math at the freshman-sophomore college level using an approach that regards logic as a basic tool -instead of as just another academic subject. We strive to give students a skill in using the propositional and predicate calculi and then to exercise that skill thoroughly in teaching other topics of discrete math. Almost all proofs are done formally, using a calculational logic in which substitution of equals for equals is the main inference rule.

In this talk, we present the calculational logic and discuss our experiences with the approach. Our main message is that this approach can do far better than the conventional one in dispelling students' fears of math and in turning students on to logic.
\end{abstract}

\section{BIOGRAPHY}

David Gries received a BS from Queens College, NY, in 1960, an MS from Illinois in 1962, and a Dr. rer. nat. from MIT (Munich Institute of Technology, now the Munich Technical University), Germany, in 1966, all in mathematics. He was an assistant professor of computer science at Stanford 1966-1969 and has been at Cornell since 1969. His research has been in compilers, programming methodology, programming languages, and logic. He is known for his texts in compiler writing (1971), introductory programming (1973), formal development of programming (1981), and logic and discrete math (1993). He holds the major education awards from ACM, ACM SIGCSE, IEEE, and IFIP and is a Cornell Weiss Presidential Fellow. 